\title{
Correction to: Endogenous Stem Cells in Homeostasis and Aging
}

\author{
Ji Eun $\operatorname{Lim}^{1} \cdot$ Youngsook Son ${ }^{1,2}$
}

Published online: 19 May 2018

(C) The Korean Tissue Engineering and Regenerative Medicine Society and Springer Science+Business Media B.V., part of Springer Nature 2018

\section{Correction to:}

\section{Tissue Eng Regen Med (2017) 14(6):679-698 https://doi.org/10.1007/s13770-017-0097-3}

Regrettably, in the previous version of this article, two important references [47-2, 173] were missing. The authors would like to make following corrections in the original version of the article:

Page 685, right panel, line 1, the previous Ref. [47] Elliott BT et al.'s Physiol Rep 2017 is now changed to the Ref. [47-1] and a newly added reference of Elliott B's Wikipedia is added as Ref. [47-2]. Thus, the sentence is changed as follows "Bradley Elliot said that "In humans, older males who had been chronically active over their lives show higher concentrations of GDF11 than inactive older men, and the concentration of circulating GDF11 correlated with leg power output when cycling" [47-1, 47-2]”.
47-2. Wikipedia: the free encyclopedia [Internet]. St. Petersburg (FL): Wikimedia Foundation, Inc. 2001 [cited 2017 October 10]. Available from: https://en.wikipedia. org/wiki/GDF11.

A part of this review contains the excerpt of author's previous publication in the chapter 5 "Roles of Endogenous Growth Factors and Small Peptides in In Situ Tissue Regeneration" in a book "In Situ Tissue Regeneration; Host cell Recruitment and Biomaterial Design". This was added as reference with publisher's reprint permission [173].

173. Kim S, Hong HS, Son Y. Roles of endogenous growth factors and small peptides in in situ tissue regeneration. In: Lee SJ, Atala A, Yoo JJ, editors. In situ tissue regeneration. 1st ed. London: Academic; 2016. p. 73-85. A part of chapter 5 was reused with reprint permission from Elsevier Inc. (Permission Order number 501358049).

The original article can be found online at https://doi.org/10.1007/s13770-017-0097-3.

Youngsook Son

ysson@khu.ac.kr

1 Department of Genetic Engineering, College of Life Science and Graduate School of Biotechnology, Kyung Hee

University, 1732 Deogyeong-daero, Giheung-gu, Yongin-si, Gyeonggi-do 17104, Republic of Korea

2 Kyung Hee Institute of Regenerative Medicine, Kyung Hee University Hospital, 24 Kyungheedae-ro, Dongdaemun-gu, Seoul 02453, Republic of Korea 